\title{
USE OF WORKFLOW-PATTERNS FOR PROCESS MODELING IN THE BUILDING INDUSTRY
}

\author{
Martin Keller, Karsten Menzel, Raimar J. Scherer \\ martin.keller, karsten.menzel, scherer@cib.bau.tu-dresden.de
}

GERMANY

\begin{abstract}
In contrast to the predefined and static processes in most industries, the design and construction processes in the building industry are extremely dynamic. Technical conflicts and modified design goals lead to ad-hoc changes within the workflow. They are no exception but usual. Therefore, common principles must be established throughout the construction industry, that allow to flexibly combining engineering and construction services. New members must be able to join and leave the project consortium on demand. The need to rapidly establish new organisational structures and effectively manage these virtual organisations places high demands on the methods used for modelling the processes. Consequentially, there is a need for an overall model-framework representing the different design, construction and management processes that integrate specialized process-and building-models used for different domains.
\end{abstract}

\section{INTRODUCTION}

Projects in the construction industry are characterized by their complexity involving various specialists like architects, construction engineers, surveyors, etc. Different aims of the participating partners will inevitably lead to a conflict in the objectives.

At the beginning of a project only general boundary conditions and basic constraints are predetermined by e.g. the investor or designer. With the progress of the project, the necessary work teams, activities and schedules most often need to be assembled or even altered in an ad-hoc fashion to accomplish the project goals.

Given the evolutionary and iterative nature of design and construction projects, process information, specifying tasks, times, roles, data, and sequences accumulate during the project, from a first schematic model to very detailed work schedules. In order to be able to work on the overall project plan at any time, it is inevitable to use distinct process models in parallel, representing the various processes in an adequate form and at an appropriate level of granularity. While the objectives of later processes are modelled more abstract, the characteristics of the processes in the near future must be precisely specified.

Graphically spoken the project information of a construction project looks like a wave. While information about activities to be conducted in the remote future of the project is very limited, information about nearby activities is very detailed. That 
means that project information will be accumulated with the progress of the project. All actives to be conducted in the future are labelled as prospective processes.

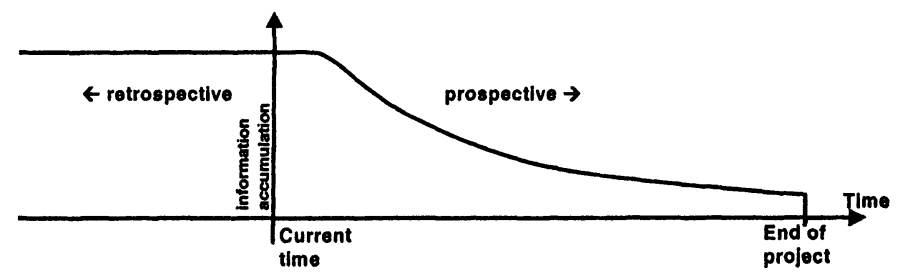

Figure 1- Information Wave in a construction design project

Conducted activities are named retrospective processes. These processes will comprise all information gathered during the performance of the project. The transition of the prospective and retrospective phase will be at present.

\section{APPROACH}

In order to establish an overall model-framework representing the different design, construction and management processes that integrate specialized process and building models used for different domains of a construction project three different criteria have to be investigate. First of all the concept of virtual organizations (VO) has to be adapted to the particular conditions of the construction industry. In addition a construction project should be structured into different layers to handle the diverse requirements of the individual roles of the partners in the VO. In a last step predefined process-pattern can be applied to the defined layers.

\subsection{Virtual Organizations in the building industry}

"A virtual Organization is an identifiable group of people or organizations that make substantially more use of Information and Communication Technologies than physical presence to interact, conduct business and operate together, in order to achieve their objectives"(8). The aim of the Virtual Organization is to gather various competencies of different companies in order to enhance efficiency and productivity while decreasing overheads. Virtual Organization can be distinguished in different characteristics like duration, topology, participation, coordination, and visibility (4). According to this a construction project can be structured as shown in Table 1.

Table 1: Classification of a construction project

\begin{tabular}{|c|c|c|}
\hline Duration: & Participation: & Coordination: \\
\hline $\begin{array}{l}\square \text { Project Cooperation } \\
\square \text { Long term alliance }\end{array}$ & $\begin{array}{l}\square \text { Single alliance } \\
\square \text { Multiple alliance }\end{array}$ & \multirow{3}{*}{$\begin{array}{ll}\square & \text { Star-like structure } \\
\square \text { Democratic Alliance } \\
\square \text { Federation }\end{array}$} \\
\hline Topology: & Visibility: & \\
\hline $\begin{array}{l}\square \text { Variable/dynamic nature } \\
\square \text { Fixed Structure }\end{array}$ & $\begin{array}{l}\square \text { Single level } \\
\square \text { Multi level }\end{array}$ & \\
\hline
\end{tabular}


Considering the specification of VOs a construction project usually has a starlike architecture coordinated by e.g. the project manager and the architect respectively. Domain specialist companies like construction engineers, earthquake engineers, etc will support him. The domain manager who in turn is supported by various engineers will act as a representative of the company.

Due to the dynamic construction design process it is almost inevitable to connect and disconnect companies over the project. Therefore, the main project information should be accessible to every partner. New members must easily be capable to gather all relevant information together with the status of the project, its milestones and overall goals.

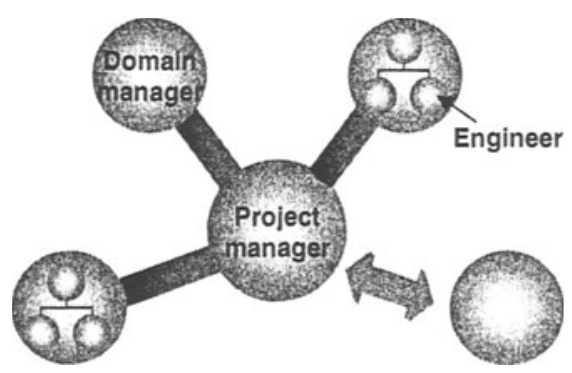

Figure 2 - Virtual Organization in the building industry

Over the entire project the phases of a virtual organization 1) partner search, 2) contract negotiation, 3) operation and 4) dissolution will continuously take place. While one partner is already leaving the project, an other partner is still negotiating with the project manager.

\subsection{Layer Concept}

A construction project is very complex. While the outcome, e.g. a bridge or office building, is fixed, the procedure to reach this goal is almost unpredictable. Only some milestones (for example the nine phases of the German $\mathrm{HOAI}^{11}$ ) might be settled. Processes within these phases are very dynamic dependent on the size and difficulty of the project.

To reduce the complexity of a project it should be separated into different hierarchical layers. Each of these layers should have its own paradigms for modelling and representing the desired information. While the top layer is giving an overview over the entire project in order to identify long term conflicts as well as to calculate and measure the performance of the project, the button layer schedules the processes in detail but with a limited coverage. Three layers of granularity with corresponding project roles can be identified as:

- strategic layer

- tactical layer

- operative layer

With the development of these three layers it is possible to decompose the complex design and construction processes into different stages of granularity. 
Every introduced layer is described with its own description model, since different demands for the process modelling are asked for. These models have to be integrated into a homogeneous domain description of the entire design and construction processes.

Table 2: Layer Concept for a construction project

\begin{tabular}{lll} 
Layer & Content & Model \\
\hline Strategic & goals, milestones & goal function \\
Tactical & formal sequences & workflow-management \\
& (business processes) & (planning \& controlling) \\
Operative & times \& resources & scheduling
\end{tabular}

\section{Strategic Layer}

The strategic layer defines the boundary conditions of the project by outlining the project aims in a goal function. Goals and their relationships should be described in a formal and definite manner with performance indicators like time, cost, resource, etc. By dividing the goals in sub-goals in accordance with the project progress, milestones can be determined. The strategic layer will provide project information nominated for the project manager. With this layer the project progress can be controlled and major conflicts with the project aims can be prevented.

\section{Tactical Layer}

By introducing the tactical layer a complex construction project can be divided into homogeneous, closed phases (milestones). These phases will gather a certain amount of activities (control cycles) required to reach the goals of the strategic layer. Within the tactical layer domain specific activities will be defined by characterising the input and the output information as well as the responsible actor for the activities. The sequence of the activities will be defined by specifying the successor and predecessor. Even activity cycles are possible in the tactical layer. The project manager together with the domain manager will manage the tactical layer.

\section{Operative Layer}

While the activities defined in the tactical layer specifying the output data needed to fulfil the requirements of a milestone, the operative layer schedules the tasks needed to fulfil the activities according to the boundary conditions of the strategic layer (e.g. time, cost, quality). Within the operational layer resource can be planned and the critical path can be calculated. The domain manager together with the engineer will manage the operational layer.

\subsection{Process Pattern}

Setting up a new project requires a lot of work and experience of the project manager. He has to establish the organizational as well as the process structure of the project. The better he knows the activities needed to fulfil the design and construction goals the less problems and conflicts will emerge during the operational phase of the project. Since he cannot predetermine every single activity required for 
the project in advance, especially for activities in the remote future, predefined processes might be of invaluable help.

A Process Pattern Library can be used for setting up the process management guidelines for new project organisations. With this architecture an evolutionary process model can be designed by instantiating the appropriated model on the fly from a database of reference processes.

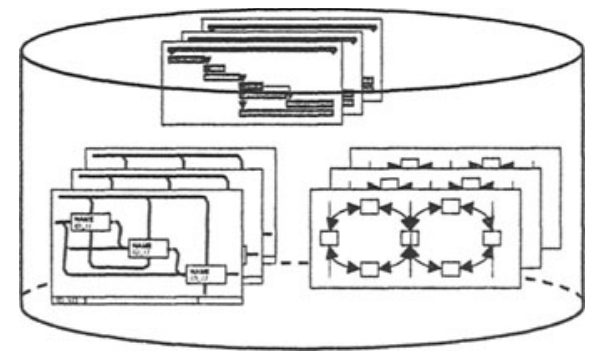

Figure 3 - Process Pattern Library

Process Pattern shall not cover the entire construction process with every single task that has to be performed, it rather should cover certain (domain specific) issues. While the sequence of the project phases can be modelled in a more general manner, defining the output data and the performing domain specialists, certain activities, like the construction analysis of a bridge pole, can be modelled in every detail. That means, in accordance with the boundary condition of the project time schedules and resources can be determined.

\subsection{Integration}

In the previous three chapters the concept of virtual organizations in the construction industry, a layer concept for construction projects and the use of process patterns has been discussed. Combining these theories will lead to an architecture that might help to support and enhance construction processes in multiple ways:

- by providing process pattern which can dynamically being instantiated during the operation of the project;

- by separating the project into three different layers reflecting different types of granularity;

- by providing different views on the project dependent on the role of the partner in the project.

Considering the prospective processes of a project, the strategic scope will be advanced at the best. Therefore, the strategic layer will need a more abstract model of the activities of the project constituting the performance indicators of the project. This layer will set the boundary conditions of the project managed by the project manager. Derived from the information of the static layer the tactical layer will specify the project phases. In cooperation with the domain manager the project manager can instantiate process from the process pattern library.

Derived from the information of the tactical layer the operational layer will specify the activities. In cooperation with the engineers the domain manager can instantiate a specific schedule from the process pattern library. 


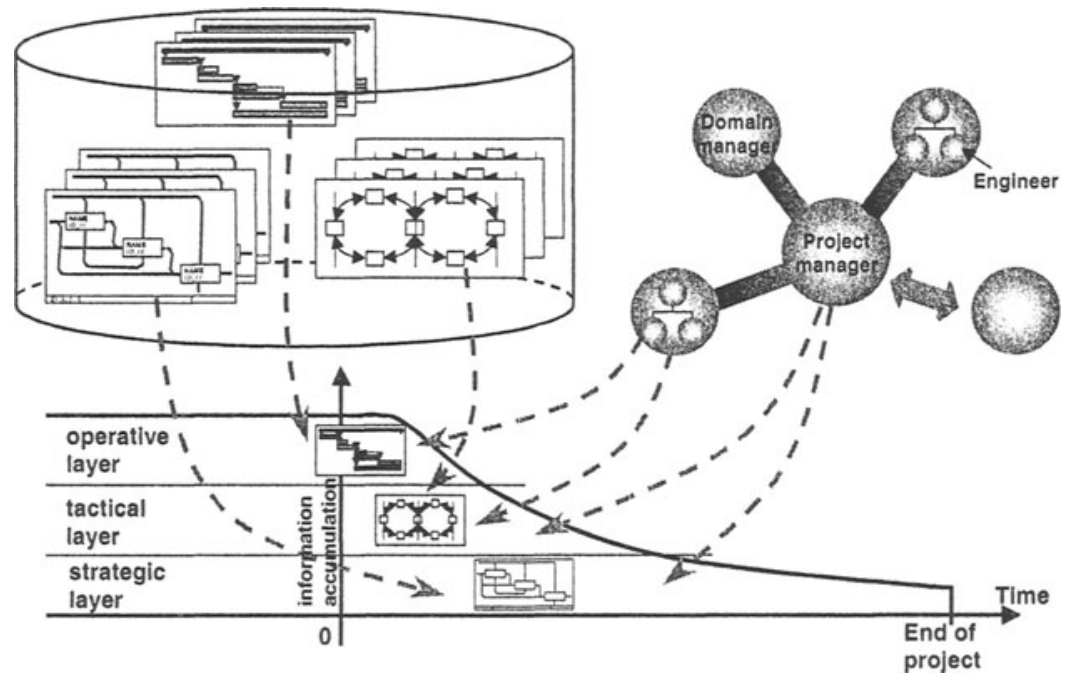

Figure 4 - Integration of processes, organization and layers

With this architecture evolutionary processes can be derived by instantiating the appropriated model on the fly from a database of reference process, which in turn will make the processes much more reliable compared to processes developed by the project manager without the help of predefined processes.

Another advantage of this architecture is that information can be adapted to a role of the actor. That means that an engineer is by far more interested in the tasks and activities related to his own task, while the project manager mostly does not want to have information about every little detail of the project, as he is much more interested in the overall progress of the project. Whether the milestones will be reached in time and whether conflicts might influence the project goals.

Last but not least this architecture will help to advance the information wave by the use of the process patterns. By analysing the project information of the retrospective processes new pattern can be derived. Therefore, the patterns are more reliable and have a deeper prospective of the future than a project manager might be able to.

\section{DEVELOPMENT OF PROCESS PATTERN}

In practice the during the design and construction process developed project information remain unused after the end of a project. Hence, the ideas and possible re-engineering thoughts are often lost or forgotten, and thus not further utilized effectively (7). Therefore, collecting the information gathered during the project might be helpful for future projects.

In order to obtain the required information the retrospective section of the information wave, introduced in chapter one, can be applied. For that purpose the conducted processes have to be allocated and afterwards divided into individual process pattern representing individual activities and phases of the project. These 
project patterns should be designed in accordance to the process models introduced in chapter 2.3. The developed Process Pattern Library can be used for setting up the process management guidelines for new project organisations.

However, not only the performed processes can be used for creating process pattern in order to have more confident in remote processes, the building itself is an excellent information basis for construction processes.

\section{Building-Product-Models}

In recent years data models for the virtual representation of constructions have been developed. These so-called Building-Product-Models are defining standardized object-orientated descriptions of a building in order to enable seamless exchange of data between construction related programs. They are not primarily oriented towards the geometrical processing; the basic idea is that the architectural design object is considered as a logical entity within the product model (6).

An example for the standardization efforts is STEP2, where application protocols are designed for data exchange of product models of building and their parts. A more recent effort is the International Alliance for Interoperability, which is defining the Industry Foundation Classes (IFC ${ }^{3}$ ) for the same purpose. The IFC model is developed with reference to object-orientated paradigms, including abstraction, modularity, generalisation and aggregation. Therefore, a decomposition of a construction is possible. For example: a building is composed of different floors, while a floor can be divided into rooms. A room in turn is surrounded by walls that may have windows, and so on.

However, not only the structure of the building can be subdivided into parts, but also different partial models can be extracted from this model to meet the requirements for the various domain specialists like architects or stress analyst. For an architect, for example a wall is primarily the boundary element of a room, while a stress analyst is mostly interested in the strength of the wall. An air-condition technologist again needs the information of the penetrability of the wall.

Comparing the proposed process-model with the existing building-productmodels a remarkable similarity can be noticed. Both models are defining the boundary conditions of the project as follows: within the process model performance indicators like time, cost, and resources are defined while technical indicators like dimension of the construction, main structure, and the aspired use of the building are elements of the product model. These main goals can be divided in sub-goals/objects to become very detailed information of the project; in addition different domain specific views can be extracted from both models.

Collecting the Building-Product-Model information developed during the construction process together with the process information can be helpful for further projects, by attaching process information to construction objects like floor, room or wall. Therefore, during the design of the building processes will be instantiated together with the matching construction object. Consequently, corresponding with the development and the refinement of the construction the prospective processes will become more reliable and of higher granularity. Furthermore, modifications in the construction can automatically indicate changes in the workflow of the project. Therefore, technical decisions will be supported by its effects on the project processes. 


\section{CONCLUSION}

The design and construction processes in the building industry are extremely dynamic. Therefore, common principles must be established throughout the construction industry, that allows to flexibly combining construction services. New members must be able to join and leave the project consortium on demand. The need to rapidly establish new organisational structures and effectively manage these virtual organisation places high demands on the methods that are used for modelling the processes. Consequently, there is a need for an overall model-framework representing the different design, construction and management processes that integrates specialized process models used for different domains.

Due to this situation the information for remote processes are very limited while closer processes can be modelled in detail. By introducing a three layer architecture divided into the strategic, tactical and operational layer the processes can be structured according to their relevance to the project goals. Corresponding to the process layers three different roles have been identified: project manager, domain manager and engineer. Each role will need individual views on the project processes. Therefore, each layer needs its own information model.

By taking advantage of predefined process patterns, new processes and changes in the design goals can easily be integrated in the overall workflow. These process patterns will be derived from completed operations and stored in a Process Pattern Library. However, not only the performed processes can be used for creating process pattern, also the Building-Product-Model information is an excellent information basis for construction processes. Corresponding with the design of construction objects new processes will be instantiated.

\section{REFERENCES}

1. Abecker A, Hinkelmann K, Maus H, Müller HJ. Geschäftsprozessorientiertes Wissensmanagement. Springer 2002, 3-540-42970-0

2. Augenbroe G. Integration directions. In the proceeding of "ecppm 2002 eWork and eBusiness in Architecture, Engineering and Construction". Portoroz 2002, Balkema, ISBN 90-5809-507-X

3. Böhm M. Entwicklung von Workflow-Typen. Springer 3-540-66394-0

4. Camarinha-Matos, L. The virtual enterprise concept, In "Infrastructures for the Virtual Enterprise Networking industrial enterprises", ISBN 0-7923-8639-6

5. Jablonski S, Böhm M, Schulze W. Workflow-Management - Entwicklung von Anwendungen und Systemen - Facetten einer neuen Technologie. dpunkt.verlag 1997, 3-920993-73-X

6. Junge R., Liebich T.Product Modelling Technology - the Foundation of Idustry Foundation Classes, In Proceedings of ECPPM'98, England, ISBN 1-86081-249-X

7. Karhu V. A generic construction process modeling method, Doctoral Thesis, Stockholm 2001, http://www.lib.kth.se/Sammanfattningar/karhu011109.pdf

8. Proceeding of the VoNet - Workshop, April 27-28, 1998 Institute of Information Systems, Department of Information Management, University of Bern

\footnotetext{
'HOAI - "Honorarordnung fur Architekten und Ingenieure", regulation to calculate the hires for performed work of architects and engineers (contractor). The HOAI structures the construction process into nine phases:

${ }^{3}$ STEP - ISO 10303 - www.iso.org

${ }^{2}$ Industry Foundation Class by the International Alliance for Interoperability; www.iai-international.org
} 